\title{
Analysis on Technical Efficiency in the Process of Exploitation Palm Oil in Lobaye Locality, Central Africa Republic
}

\author{
Francine Josee Derebona Ngaisset, Xianping Jia \\ College of Economics and Management, Northwest A\&F University, Yangling, China \\ Email: francined72@yahoo.com, jia.xiangping@outlook.com
}

How to cite this paper: Ngaisset, F. J. D., \& Jia, X. P. (2020). Analysis on Technical Efficiency in the Process of Exploitation Palm Oil in Lobaye Locality, Central Africa Republic. Open Journal of Social Sciences, $8,474-488$.

https://doi.org/10.4236/jss.2020.85032

Received: April 22, 2020

Accepted: May 26, 2020

Published: May 29, 2020

Copyright $\odot 2020$ by author(s) and Scientific Research Publishing Inc. This work is licensed under the Creative Commons Attribution International License (CC BY 4.0).

http://creativecommons.org/licenses/by/4.0/

\begin{abstract}
The present was carried out of Technical Efficiency in the Process of Exploitation Palm Oil in Lobaye Locality, Central Africa Republic. Primary data used in the study were collected through well-structured questionnaire administered with 150 randomly selected oil palm processors in the study area. Descriptive statistics, analysis and the Stochastic Frontier Production Function were used to analyze the data. The average technical efficiency of agricultural production by farmers on a variable scale of yield is 0.81 . This means that agricultural production will increase by $0.68 \%$ compared to the current level of inputs. The result shows that $0.95 \%$ of the sample is the technical efficiency of the variable scale inputs. This means that agricultural production can be increased. Results have shown that productivity is significantly influenced by producer education in the area of yield. It is recommended that policies improve the training of producers in order to build capacity to continuously increase their regular production.
\end{abstract}

\section{Keywords}

Palm Oil, Technical Efficiency, Production, Process Exploitation, Lobaye Prefecture

\section{Introduction}

Technical efficiency of farmers in the production of palm oil in Central African Republic (Laboye area) is used primary and secondary for Collection data. Its objective is to improve the technical efficiency of palm oil production and vice versa to maximize the use of fewer inputs to achieve the maximum possible exit while maintaining a good environment and protecting the ecosystem (FAO, 
2016). The agricultural sector is said to be the most important sector in most low-income countries. Smallholder farming is a dominant driver of high-intensity productive growth. The change and motivation of the farmers make it possible to improve technical efficiency with all inputs in order to produce more output. Agriculture in the Central African Republic is based on the wider economy, including livestock, forests, hunting and fishing, which accounts for about 50 per cent of GDP and more than 40 per cent of export earnings. CAR is self-sufficient in food as well (Porter, 1998). The rate of production of palm oil is lower than the annual increase in population. It is therefore necessary to improve the technical efficiency of the farmers employed, in order to respond that technical efficiency requires an improvement in the potential of the farmers employed and in productivity. By improving their development skills, management practices and education could be a factor in increasing productivity through the efficient use of technology and resources. The Central African Republic ranks fourth in the ranking of the least wealthy countries in the world. CAR has a GDP of \$2.29 billion, with a GDP per capita of 441 undernourished people. The population was 5.18 million in 2019 (Huang \& Liu, 2020). Agriculture is the main driver of the CAR economy, with $75 \%$ of people working in the sector contributing more than $50 \%$ of the country's GDP. In 2008, 62\% of the population of Central Africa was living below poverty. Africa's economy is growing by 3.4 per cent in 2019 and 4.1 per cent in the first quarter of 2020. The continent is the current and future productive base, while improving the labor productivity of Africa's Development Bank 2020, Africa for the Future Collaborative Labor Force (Forrest, 2019). The agricultural production of palm oil plays a very important role in the CAR (Central Africa Republic). Socio-economic indicators follow the economic circle and social change, and generally describe the well-being and quality of life of people. The increase in agricultural production helps to reduce rural areas and improve people's livelihoods and stimulate economic growth that generates productive jobs and generates income. Output estimates that the average value will increase by 0.81 , indicating that palm oil productivity is 81 per cent or that the average technical efficiency would have reached the highest technical level of 96 per cent. And yield would be more advantageous than average results of an ineffective technical reduction in palm oil production; thus, self-sufficiency could lead to increased production growth. Production is lower, farmers are inefficient and technical, and palm oil production will be inadequate. Decreased production has an impact on the environment and economic growth. Palm oil is a natural crop originating from Africa (Appelbaaum, Bailey, Berg, \& Kalleberg, 2000). Palm oil is produced in oil from palm fruit pulp. The main advantages of vegetable palm oil are numerous; olive growing has the highest yield and is very efficient and cheaper than sunflower oil, soya bean, and rapeseed. Palm oil produces oil 4 to 10 times as much as any other oil. The relationship between education and culture is, first and foremost, of great importance for palm oil in the social, economic and cultural activities of the people of Africa. It also shows, however, that the oil palm has been beneficial when it is included in a diverse, 
decentralized, man-made system, but it is dangerously developed in accordance with a centralized system, Monoculture and business-driven model (Bravo-Urta \& Pinheiro, 1993). The relationship between education and culture is, first and foremost, of great importance for palm oil in the social, economic and cultural activities of the people of Africa. It also shows, however, that the oil palm has been beneficial when it is part of a diverse, decentralized, man-made system, but it is dangerously developed in accordance with a centralized, monoculture and business-oriented model. As a result, entire communities may face the displacement of their land, the destruction of their livelihoods, the replacement of their various ecosystems with oil palm monocultures, and trade in palm oil, especially for women's income from palm oil. The economic importance of oil palms to Africa is enormous, especially in the case of women. They handle most of the production, harvesting and processing of palm oil for sale in the local oil and other palm oil markets (Dennis \& Romanus, 2018). For example, in Guinea, the oil palm sector is still a stable source of employment and therefore contributes to stemming the rural exodus and developing the local economy (Tafti, Shahnaz, \& Emami, 2012). Farmers have used new innovations and benefits that can be achieved when adopted. Technical efficiency is the possibility for the farmers employed to obtain the maximum authorized output from accessible sources. However, it was only through adaptation and innovative technologies that the objective growth of production could not be achieved, but above all through the efficiency in which technologies are used (Wanke, Chen, Zheng, \& Antunes, 2020). In this way, policy makers and researchers recognize the importance of efficiency as a means to increase production. Empirical evidence from different sources Research shows that the gap between actual and potential output can be closed by using fewer inputs to achieve the maximum output possible (Ojo \& Ajibefun, 2000). The reason for the variation is to pursue the different management practices of farmers (Kumbhakar, Ghosh, \& McGuckin, 1991). The possibility of productivity efficiency is realized on the basis of their level of efficiency, Education. New knowledge of employed women farmers would have an effective technical increase in inputs and output for better performance (Abdulsalam, Nandi, \& Ahmed, 2014). The objective of this analysis of this model is to estimate on the basis of the palm oil exploitation process in Lobaye Prefecture. In this article, we applied a stochastic border approach to the assessment of the efficacy of the level of income of farmers. Based on the results of estimates of technical efficiency using the stochastic border model, some recommendations are made in the production process. The objective of this study is to analyze the factors that influence the efficacy of the study. Reason Influence on technical efficiency in production, literature points out that a decline in the rate of production is a major reason for their failure, and more efficient technical production could reduce the unemployment rate and the poor. It is both traditional and modern. It plays a key role in environmental and climate change. Farmers' technical efficiency plays an important role in the regular production process and facilitates an increase in the likely yields to analyze the nature of the technical effi- 
ciency of palm oil production; to challenge the factors that have an impact on the organization of palm oil cultivation.

\section{Literature Review}

Several kinds of literature are appropriate for our study. It's the Function of production, identification of methods and determinants of exploitation of palm oil production procedures. Next, look at a sample of 150 employees. The method uses a variety of approaches in modeling translog cobb-Douglas this analysis is much used in the case of the production function to determine, the positivity of marginal factor issues: this condition ensures, the increase of a factor is accompanied by an increase in production. Consist of two identifies the existing production-minimum of inefficiency and a maximum level of capacity in an entity no longer producing companies (Lorenz \& Valeyre, 2005). The efficiency of the production describes good production. Assessing the importance of the productive agricultural industry was a measure of the production and inputs of our economic values. A company's efficiency was its ability to create a large number of production options on a fixed amount of inputs. Thus, an efficient company was one that, in terms of knowing new techniques, can create a given number of productions using the least inferiority of inputs. The country's business processes are influenced by many macro and microeconomic factors, including labor and capital policies, the state of better fiscal management facilitates the growth of the country's economy through unemployment, productivity, exchange rate, inflation and many other dynamic diversification industries, economic performance the strategy of diversification into traditional industries. Palm oil and palm kernel have contributed the most, with 48 million tons or $30 \%$ total production. Soybean oil came in second with 37 million tons of $23 \%$. Approximately $38 \%$ of the world's oils and fats have been shipped across the oceans. 60 million tons account for $60 \%$ of the oil and palm oil exported worldwide. The aim of research worldwide is to emphasize that palm oil may not be a healthy substitute for fatty acids of Tran. In 1962 and 1982, world exports amounted to half a million to 2.4 million tons per year. World production of palm oil and palm oil was 48 million tons in 2008. In the world of oil, FAO 2020 needs to reproduce and triple. Invalid source has been specified. Efforts, therefore, to improve the technical effectiveness of the cooperative's role among its members and the participation of palm oil producers in the plasma model.

\section{The Stochastic Frontier Analysis (SFA) Approach and the Tobit Model}

\subsection{The Stochastic Frontier Production Model}

$$
Y_{i}-f(\beta)+t l, i=1,2, \cdots, n
$$

where, $Y_{i}$ denotes the output for the null farm $(i=1,2, \cdots, n) ; S_{a}$ is a $(1 \times P)$ vector of factor inputs of the null farm and $\beta$ is a $(S \times 1)$ vector of unknown parameters to be estimated; $\varepsilon_{a}$ is the error term that was two elements, namely: 


$$
\varepsilon_{a}=V_{a}-U_{a}
$$

where, $V_{a}$ was random variables which had assumed to be independently and identically distributed $N\left(0, \sigma_{v}^{2}\right)$ and independent of the $U_{a}$ and can have positive or negative. The term $U_{a}$ was a non-negative random variable which accounts for pure technical inefficiency in production and is assumed to be independently distributed as truncations of the $N\left(Z_{a} \delta, \sigma_{u}^{2}\right)$ distribution (Aigner et al., 1977). The assumption of the independent distribution between $U_{a}$ and $V_{a}$ allows the separation of the stochastic and inefficiency effects in the model. Battese defined $U_{a}$ as:

$$
U_{a}=Z_{a} \delta-W_{a}
$$

where, $Z_{a}$ is a $(1 \times p)$ vector of variables affecting farm efficiency; $\delta$ is a $(p \times 1)$ vector of parameters had estimated; $W_{a}$ represent the truncation of the normal distribution with mean 0 and variance $\sigma_{u}^{2}$, in such a way that the point of truncation is $-Z_{a} \delta$, i.e., $W_{a} \geq-Z_{a} \delta$. These assumptions were consistent with $U_{a}$ being a non-negative truncation of the $N\left(Z_{a} \delta, \sigma_{u}^{2}\right)$ distribution.

The maximum likelihood estimation technique is used to simultaneously estimate the parameters of the stochastic frontier model in (EQ1) and those for the technical inefficiency model in Equation (3). The parameters in (EQ1) include $\beta$ and variance parameters such as $\sigma^{2}=\sigma_{u}^{2}+\sigma_{v}^{2}$ and $\gamma=\sigma_{u}^{2} / \sigma^{2}$ (Battese \& Coelli, 1988). Where, $\sigma^{2}$ is the sum of the error variance, $\gamma$ measures the total variation of output from the frontier that attributed to the existence of random noise or inefficiency. The value of $\gamma$ lies between zero and one. Inefficiency is not present when $\gamma=0$ which means that all deviations from the frontier had due to random noise. However, if $\gamma=1$ then the deviations were completely caused by inefficiency effects (Batese \& Coelli, 1995).

The farm level technical efficiency of production for the null farm $\left(T E_{a}\right)$ is defined as:

$$
T E_{a}=\exp \left(U_{i}\right)=\frac{Y_{i}}{f\left(X_{a} ; \beta\right) \exp \left(V_{a}\right)}
$$

The estimate of the technical efficiency was based on the conditional expectation expressed in Equation (4), given the model specification (Battese \& Coelli, 1988). The parameters for the stochastic production frontier model in (EQ1) and for the technical inefficiency model in Equation (3) were estimated simultaneously with Maximum Likelihood Estimation (MLE).

\subsection{Empirical Model Estimation}

The stochastic production frontier model for shrimp pond culture in Peninsular Malaysia has employed the Cobb-Douglas functional form, which has been commonly used in other aquaculture studies in developing countries ( $\mathrm{Hwu}, \mathrm{Fu}$, \& Tsay, 2016). The empirical model is represented by Equation (EQ5) below:

$$
\ln Y_{a}=\beta_{0}+\beta_{1} \ln S_{1}+\beta_{2} \ln S_{2}+\beta_{3} \ln S_{3}+\beta_{4} \ln S_{4}+\beta_{5} \ln S_{5}+\beta_{6} \ln S_{6}^{2} V_{a}-\mu_{a}
$$


where, $\ln$ is the natural logarithm, $\beta$ 's are the regression coefficients of inputs (input elasticities) and $V_{a}+U_{a}$ are the error terms. The definitions, measurements and summary statistics of all the variables in (EQ5) are presented in Table 2. Maximum likelihood estimation of (EQ5) provides the estimates for the $\beta$ 's and the variance parameters, $\sigma^{2}=\sigma_{v}^{2}+\sigma_{u}^{2}$ and $\gamma=\sigma_{u}^{2} / \sigma^{2}$. The empirical specification for the random variable associated with technical inefficiency (EQ5) is shown in (EQ6):

$$
\mu_{a t}=\delta_{0}+\delta_{1} R_{a 1}+\delta_{2} P R_{a 2}+\delta_{3} P R_{a 3}+\delta_{4} R_{a 4}+\delta_{5} R_{a 5}+E
$$

The definitions, measurements and the summary statistics for variables $S_{1}$ to $R_{a t}$ are presented in Equation (EQ6) can be estimated if the technical inefficiency effect, $\mu_{a t}$ are stochastic and have particular distributional properties ( $\mathrm{Hwu}, \mathrm{Fu}$, \& Tsay, 2016). Therefore, it is necessary to test for the absence of technical inefficiency effects by testing a number of hypotheses. The first hypothesis is $\gamma=\delta_{0}=\delta_{1}=\delta_{2}=\delta_{3}=\delta_{4}=0$; that is the effects of the technical inefficiency are not present in the model, the second hypothesis is $\gamma=0$, to test whether technical inefficiency is deterministic. Rejection of the null hypothesis indicates that the $\mathrm{U}$ term should be included in the model. The third hypothesis is $\delta_{1}=\delta_{2}=\delta_{3}=\delta_{4}=0$, is that the technical inefficiency effects follow a standard truncated normal distribution with no technical inefficiency effects. This hypothesis is used to test whether or not the technical inefficiency function, Equation was influenced by the level of explanatory variables. The fourth hypothesis $\delta_{0}=\delta_{1}=\delta_{2}=\delta_{3}=\delta_{4}=0$ is that the technical inefficiency effects are not stochastic. The null hypothesis can be tested using the generalized likelihood-ratio statistic, $\lambda$ given by

$$
\lambda=-2\left[\ln \left\{L\left(H_{0}\right)\right\}-\ln \left\{L\left(H_{1}\right)\right\}\right]
$$

where, $L\left(H_{0}\right)$ and $L\left(H_{1}\right)$ denote the values of likelihood function under the null $\left(H_{0}\right)$ and alternative $\left(H_{1}\right)$ hypotheses, respectively. If the given null hypotheses are true, $\lambda$ has an approximate $\chi^{2}$ distribution. In addition, when the null hypothesis involves $\gamma=0, \lambda$ has a mixed $\chi^{2}$ distribution and the critical values can be found in (Abdulsalam, Nandi, \& Ahmed, 2014).

\subsection{Technical Efficiency}

From the model estimation results, the output for each farm can be compared with the frontier level of output given the level of inputs employed. This deviation indicates the level of inefficiency of the firm. Therefore, the technical efficiency score for the null farm in the sample $\left(T E_{a}\right)$, can be defined as the ratio of observed output to the corresponding frontier output (Battese \& Coelli, 1988). that is:

$$
T E_{a}=\exp \left(U_{a}\right)
$$

where, $T E_{a}$ is the technical efficiency of the farm $\left(0<T E_{a}<1\right)$. When $U_{a}=0$ then 
the null farm lies on the stochastic frontier and is known as technically efficient. If $U_{a}>0$, the farm a lies below the frontier, which means that the farm is inefficient.

The prediction of technical efficiencies is based on the conditional expectation of $U_{a}$ in (Equation (EQ6)). The equation gives the value of $V_{a}-U_{a}$ evaluated at the maximum likelihood estimates of the parameters in (Equation (EQ5)). The parameters of the stochastic production frontier model (Equation (EQ5)) and those of the technical inefficiency model (Equation (EQ6)) are simultaneously estimated using the maximum likelihood technique.

\section{Research Methodology}

\subsection{Data Collection}

The area selected for the study was Lobaye locality in the eastern region of Capital Bangui Central African Republic. The area selected for the study was the locality of Lobaye in the eastern region of the Central African Republic of Capital Bangui. It lies between latitudes 4 and 9 to the north and lengths 17 to the east and 30 to the east (Figure 1). The study area covered a total area of $19,235 \mathrm{~km}^{2}$ with a population of approximately 246,875 (UNDP-Madagascar, U. N. D. P., 2003). Data Collection authors use primary data (Questionnaire) and secondary data (Survey) sampling of individual farmers to obtain information on the production of palm oil. Use 150 responses for the data collected. Surveys examine and select samples of individual farmers to obtain information on the production of palm oil. Use 150 responses for the data collected.

Analysis Primary data collection methods and secondary data collection methods. Questionnaire used for data collection. Surveys are examining and selected samples of individual farmers' employees to obtain information about production palm oil. Use 150 observations for data collected.

\subsection{Data Analysis}

After a visit to Palm Oil production in the locality of Pissa. Oil palm products cultivation is a natural and long-term plant. The technical method of the sample was chosen to determine the size of all quantitative information. Two types of random probability and hazard. The sampling technique is based on the statistical theory that each member of the employee's farmer must take into account. All the data obtained throughout the data will be reliable tires for the production of palm oil in the area.

\subsubsection{Framework Concept}

The scientific framework in the field of science takes the form of illuminating some of them. Improving the health of the people, food security and the potential for generation (Wu et al., 2020). Technical efficiency is important when a sharp increase is higher when there is a steady growth in production. Efficient technical production function is due to the performance of employed farmers. 


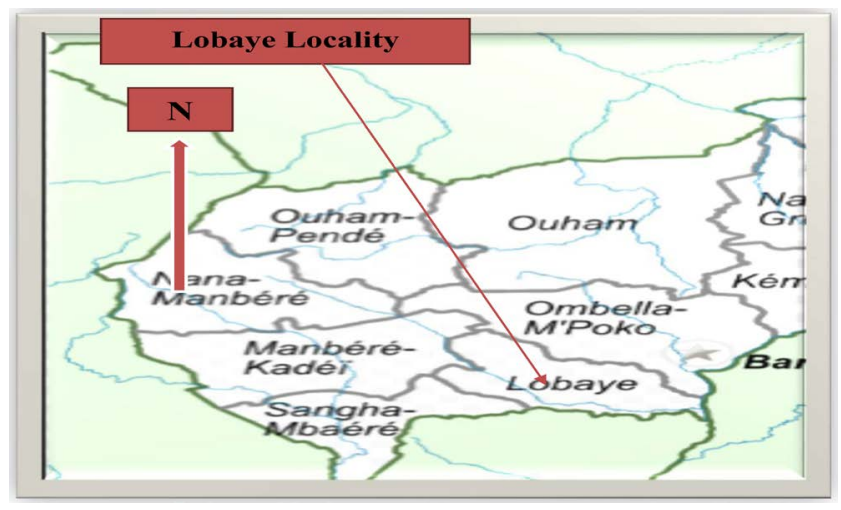

Figure 1. The study area (Lobaye Locality). Source: Capital Bangui Central African Republic, March, 2018.

The satisfaction of employee farmers had an advantage and improved productivity in the long run. Using fewer natural resources will have an effective way to make lasting change. The educational level reinforcement of agricultural employees allows a profitable increase through learning new training experts in the field of sustainable adapts technology (Takeshima, Nin-Pratt, \& Diao, 2013).

\subsubsection{Data Analysis}

The decision was based on the technical efficiency of farmers in the production of palm oil. Data use primary and secondary, modeling is quantitative and qualitative. Revenues are categorized on a nominal and a digital ordinary scale. The system is based on the cobb-Douglas production function and the bias theory of Analysis to evaluate whether the hypothesis is true or false, tools used to measure the efficiency and technique of farmers, we use Excel and Stata. The givens are interpreted in different tables and figures by the number and digital gives for the purpose of determining the justification result, and comparative. Model of stochastic border production to estimate the technical efficiency of palm oil production. It was used to estimate the technical efficiency of palm oil production. A production border model without a random component can be written. This method separates the negative impacts of technical inefficiency from those factors that cannot be controlled by farmers. The selection of linear function will be the first issue faced with the standard of the stochastic border production model. It is desirable to choose that functional form which meets economically reasonable constraints and which does not present unreasonably complex estimation problems (Fuss, McFadden, \& Mundlak, 1978). The present study approximate technical efficiency within the framework of the Cobb-Douglas stochastic border production function. Cobb-Douglas production of linear model has been used for its ease of interpretation and estimation. In addition, flexible functional forms raise the issue of multi-collinearity. Table 1 shows the descriptive of all those analysis statistics energizers those variables. The recorded average production yield is 7.81 tons per year with standard deviation 0.98 ranging from 4.71 to 9.43 . 
Table 1 . The summary descriptive production palm oil.

\begin{tabular}{lcccc}
\hline Variable & Mean & Std. D & Min & Max \\
\hline Yield & 7.819 & 0.980 & 4.710 & 9.432 \\
Seed & 2.071 & 0.302 & 1.549 & 5.367 \\
Urea & 5.360 & 0.197 & 4.605 & 5.991 \\
Hybrid seed & 0.68 & 0.4680 & 0 & 1 \\
Machine & 0.553 & 0.498 & 0 & 1 \\
Pesticide & 0.56 & 0.498 & 0 & 1 \\
Water & 0.373 & 0.485 & 0 & 1 \\
Age & 34.58 & 5.715 & 23 & 50 \\
Experience & 22.866 & 4.955 & 16 & 32 \\
Education & 6.76 & 4.516 & 0 & 14 \\
Credits & 0.586 & 0.494 & 0 & 1 \\
Gender & 0.626 & 0.485 & 0 & 1 \\
\hline
\end{tabular}

The average or maximum cultivated palm oil production company is 2.07 Seeds under palm oil are 1, 55 to 5.9 Urea, varying from 4.60 to 5.99 Urea. Deviation of 5.36. Average of Hybrid Seed 0.68 and standard deviation 0.46 from 0 to 1. Likewise, the machine average was 0.55 with the lower of zero while the higher of (1) was 0.49 . The average pesticide user was 0.56 with Std D of 0.49 ranging from 0 to 1 per $\mathrm{kg}$. The average water used by the farmer was $0.37 \mathrm{Std} D$ and 0.4 from 0 to 1 . The average age of palm oil growers was 34.58 , with 5.71 of the total number of farmers aged 23 to 50 . The average farm experience was 22.86 , with a standard deviation of 4.95 ranging from 16 to 32 . The mean calculated educational value was 6.76 , with a standard deviation of 4.51 ranging from 0 to 1 . The dummy variable was implemented the average use of credit was 0.58 with the lesser of 0 while the larger was 1 .

\subsection{The Model Specification}

Results for the Maximum Probability Estimate (MLE) indicator for the results of the technical efficiency of the experimented farmers and district (Lobaye). The analysis described that the clarification of variables, i.e. palm oil yield, pesticide and water yield, had a positive relationship with palm oil production found to be statistically significant. Means technical efficiency for the first group is 53 ranges of technical efficiency, 0,71 to 0,80 , for the second group is 37 ranges TE 0,81 to 0,91 , for the third group is 30 ranges TE, 0,91 to 100 , and for the 18 ranges, 0.60 to 0.70 the last group (Figure 2).

The results of the technical efficiency of the sampled farmer are shown in Table 2 . The analysis showed that the explanatory variables, i.e. Revenue, Urea, pesticide, palm oil water, had a positive relationship with palm production and was found to be statistically significant, and Seeds, Hybrid seeds, Machine with a negative coefficient did not contribute to efficacy. The estimated elasticity of these variables showed an increase of $1 \% .100$ hectares of yield under palm oil 
production, age, experience, credits genre, would increase yield by productivity by $0.046,0.1204,0.0296,0.855,0.7855$. As a result, the education of farmers employed in production was negative 0.029 possibilities for agriculture to grow to capacity for development.

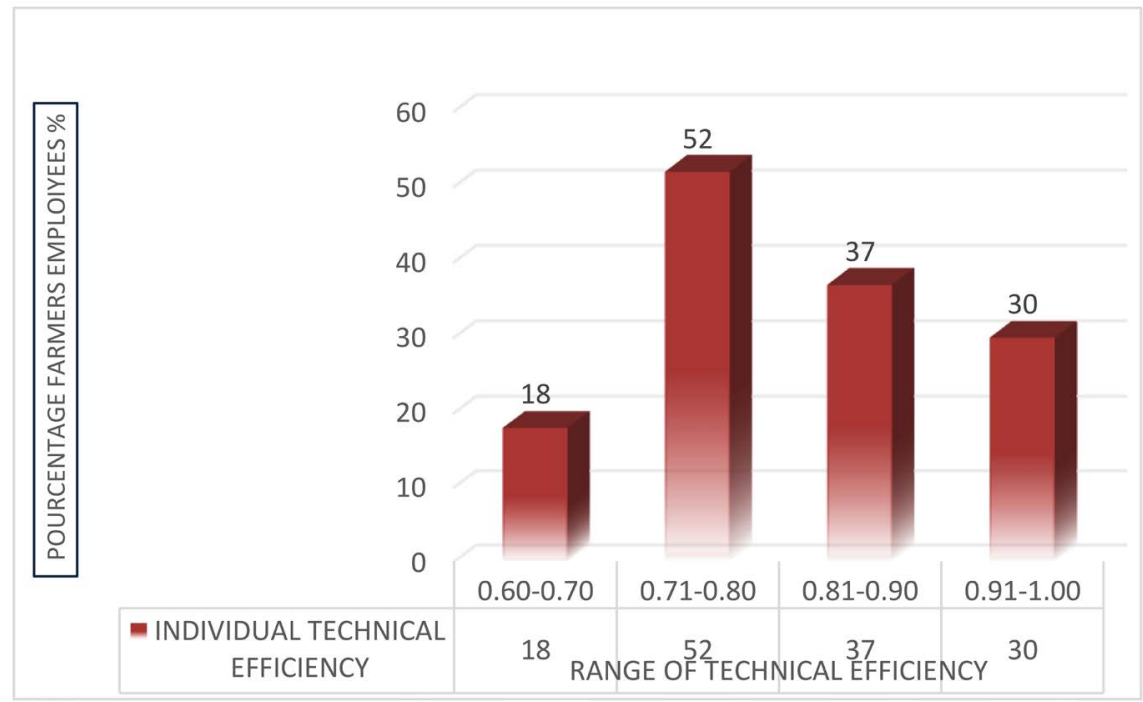

Figure 2. Distribution individual of farmers of the technical efficiency.

Table 2. Results of sample farmer's employee's palm oil in Lobaye.

\begin{tabular}{|c|c|c|c|c|c|}
\hline Varieties & $\mathbf{P}$ & Coef & Std.Err & $\mathrm{T}$ & $\mathrm{P}>/ \mathrm{T}$ \\
\hline cons & $\beta_{0}$ & 9.418212 & 4.836322 & 1.95 & 0.51 \\
\hline Ln Yield ha & $\beta_{1}$ & 0.5414945 & 0.4543077 & 1.19 & 0.233 \\
\hline Ln Seeds & $\beta_{2}$ & -8.638435 & 1.893429 & -4.56 & 0.923 \\
\hline Ln Urea & $\beta_{3}$ & 0.5661833 & 5.86714 & 0.10 & 0.923 \\
\hline Ln Hybirdseeds & $\beta_{4}$ & -0.8013257 & 0.1194977 & -6.71 & 0.000 \\
\hline Ln Machine & $\beta_{5}$ & -0.547104 & 0.1047935 & -0.52 & 0.602 \\
\hline Ln Pesticide & $\beta_{6}$ & 0.2156061 & 0.860778 & 2.50 & 0.012 \\
\hline Ln Water & $\beta_{7}$ & 0.0325268 & 0.0921655 & 0.35 & 0.724 \\
\hline \multicolumn{6}{|c|}{ Technical Efficiency } \\
\hline cons & $\delta_{0}$ & 7.836626 & 0.557152 & 1.98 & 0.047 \\
\hline Age & $\delta_{1}$ & 0.0462452 & 0.32271 & 1.43 & 0.152 \\
\hline Experience & $\delta_{2}$ & 0.1204953 & 0.348967 & 3.45 & 0.001 \\
\hline Education & $\delta_{3}$ & -0.0296936 & 0.0279396 & -1.06 & 0.288 \\
\hline Credits & $\delta_{4}$ & 0.855612 & 0271907 & 3.15 & 0.002 \\
\hline Genre & $\delta_{5}$ & 0.7855652 & 0.2735689 & 2.87 & 0.004 \\
\hline Sigma V & $\sigma \mathrm{v}$ & 0.2278701 & 0.0382544 & & \\
\hline Sigma v & $\sigma \mathrm{u}$ & 0.2549661 & 0.0503906 & & \\
\hline Gamma & $\gamma$ & 0.2468036 & & & \\
\hline Mean TE & $\mathrm{Mn}$ & 0.81 & & & \\
\hline Minimum TE & Min & 0.68 & & & \\
\hline Maximum TE & $\operatorname{Max}$ & 0.95 & & & \\
\hline
\end{tabular}


As a result, production drops are almost statistically negligible. Because farmers' education has improved knowledge in the agriculture industry and a rapid and productive change. As a result of the individual's ability to produce palm oil, the value of the palm oil was being estimated. Technical efficiency ranges from max. and min. 95 per cent to 68 per cent for farmers employed in surveys with an average TE of $81 \%$. This means that if the average sample farmer could achieve the most efficient technical efficiency possible, the average farmer would increase the yield by $15 \%$ from $81 / 95$ to 0.1473 . Similarly, the most technically inefficient farmer employed had to improve Productive output of 28 percent 1 plus $68 / 95-0.2842$. These results are consistent with the conclusions of this negative coefficient due to a reduction in the inefficient production by a non-competent farmer leading to poor production management. Use the (Tey, Brindal, Darham, Sidique, \& Djama, 2020) button to add citations to this document. Average technical competence of this study compared to other studies I found that the average technical efficiency was not far from the results.

\subsection{The Model Specialization}

The specialization consists of the selection of a method suitable for parametric and non-parametric purposes. The parameter treats the superiority of the set of data to be found more than the true hypothesis, and its data is taken from the physical person. The disadvantage of both methodologies is that the non-parametric virtues are minus the inferior hypothesis on the set of data. Parameter and non-parameter models allow statistical model functionality, technical efficiencies and their determinants to be estimated using a one-step maximum-likelihood estimate ( $\mathrm{Hwu}, \mathrm{Fu}, \&$ Tsay, 2016). Normal distribution, explained by a strong regularity technique, increases the efficiency of the production function and a non-normal distribution will cause the poor technique to reduce the efficiency of the production (Battese \& Coelli, 1988).

\section{Results and Discussions}

\subsection{Parameter Estimates}

MLE results of the experimented agricultural Table 2 signify MLE results of technical efficiency of the experimented farmer in Lobaye district. The analysis scribed that clarifying variables, the coefficient for input yield under palm oil, pecticid and water, is positive relationship with palm oil production found statistically significant. The estimated elasticity for these variables found that one percent increase in under palm oil yield use one year. Results show that per-hectare output in seed is positively related to production palm oil.

\subsection{Technical Inefficiency Model}

$$
\lambda=-2\left[\ln \left\{L\left(H_{0}\right)\right\}-\ln \left\{L\left(H_{1}\right)\right\}\right]
$$

where, $L\left(H_{0}\right)$ and $L\left(H_{1}\right)$ denote the values of likelihood function under the null 
$\left(H_{0}\right)$ and alternative $\left(H_{1}\right)$ hypotheses, respectively. If the given null hypotheses are true, $\lambda$ has an approximate $\chi^{2}$ distribution. In addition, when the null hypothesis involves $\gamma=0, \lambda$ has a mixed $\chi^{2}$ distribution and the critical values can be found in (Abdulsalam, Nandi, \& Ahmed, 2014).

Results in Table 3 show that the distribution of the individual farmers' analysis of this production is estimated to have an average value of 0.81 per cent of palm oil productivity, i.e. 81 per cent. This average technical efficiency will have reached the most technical level of $95 \%$ and the yield will be more advantageous than the average. The lowest efficiency was $68 \%$ or less. This study shows analyzes and interpretations Distribution, first, of the estimated values of the efficiency technique Achieving the future objective. Producers selected by different categories of classification, frequency and percentage, medium Employees Farmers using a sample selected at the maximum number in the Lobaye district chosen in the municipality of Pissa are 52 agricultural workers with an estimated value of $37.96 \%$, i.e. an effective relationship between 0.71 and 0.80 . Then, it indicates that the farmers are exploiting a strong technical Regular strong trend and production decision on a scale of $10 \%$. According to that, the category class in the median range of their efficiency is 0.81 to 0.90 , with a steady tendency to increase productivity by 10 per cent or about 37 farmers, with an average estimate of $27.01 \%$. Line class category has a mean value of 21.90 percent or an interval of between 0.90 and 1.00, with a number of 30 farmers operating. This means that the farmers will continue to pursue their objectives. Then 18 employees' farmers explain an average of $13.14 \%$, with an estimated value of $0.60 \%$ to $0.70 \%$.

\section{Conclusion and Recommendation}

The aim of the present study was to predict the values of the technical efficiency of farmers affecting palm oil production in the Central African Republic and to identify unobserved variables affecting technical efficiency. This analysis means that if the average sample farmer could achieve the most efficient technique, the average farmer would increase the yield by $15 \%$ (81/95) 0.1473 . Likewise, the most technically inefficient farmer had to improve productive output by $28 \%, 1$ plus 68/95 0.2842. These results are consistent with the conclusions of this negative coefficient, possibly due to a reduction in the inefficient production by a non-competent farmer leading to poor production management.

Table 3. Distribution of individual farmers employees according to technical efficiencies in central Africa Republic.

\begin{tabular}{lcc}
\hline Efficiency & Frequency & Percentile \\
\hline$\leq 0.60-0.70$ & 18 & 13.14 \\
$0.71-0.80$ & 52 & 37.96 \\
$0.81-0.90$ & 37 & 27.01 \\
$\geq 0.91-1.00$ & 30 & 21.90 \\
Mean TE & 0.81 & \\
\hline
\end{tabular}


The results of the technical inefficiency model indicate that experience and education of farm managers were major factors affecting the technical inefficiency of Lobaye Palm Oil Prefecture. In order to improve the technical efficiency of their farmer, information by extension and training farmer, managers should be provided with the aim of changing their skills and knowledge related to production.

Result indicated the inefficiency of the variable used for education and age of farmers. Their means are poor negative and the inefficiency of certain indicators in production decrease is negligible. First of all, experience has shown that the evolution of the elderly influences negatively on society, the physical strength of men is a variable, and negative influence can reduce the ineffectiveness of palm oil production. Technical inefficiency is negative for the process of exploitation of palm oil in the Central African Republic, which is changed possibly if and only if the exploitation of palm oil is significant in percent. Palm oil is a positive factor of modern efficiency in the areas. This implies that the farmer employees were strictly technical and efficient. Sustainable farming practices and food systems, including production and consumption must be pursued from a necessary and integrated point of view. Land, healthy soils, genetic resources of water and plants are key inputs of food production, and the increasing scarcity of their country makes use of it and distribution.

My recommendation is to improve the conditions necessary for farmers, and ensure an efficient and technical agricultural production policy for the environment. The financing mechanisms and controls make it possible to achieve effective technical sustainability of agriculture, infrastructure and rural development sectors, empowering farmers. Rapid change in the production of more farmers improves the education of better-acquired farmers.

\section{Acknowledgements}

This paper and the research behind it would not have been possible without the exceptional support of my supervisor, Jia Xianping. His enthusiasm, knowledge and exacting attention to detail have been an inspiration and kept my work on track from my first encounter with the final draft of this paper. Currently resides, not only provided color images of the manuscript overnight, but unexpectedly shared the invaluable information on the Paper. I am also grateful for the insightful comments offered by the anonymous peer reviewers at Paper. The generosity and expertise of one and all have improved this study in innumerable ways and saved me from many errors; those that inevitably remain are entirely my own responsibility.

\section{Conflicts of Interest}

The authors declare no conflicts of interest regarding the publication of this paper.

\section{References}

Abdulsalam, Z. N., Nandi, J. A., \& Ahmed, B. (2014). Technical Efficiency Differentials in 
Oil Palm Processing Technologies in Cross River State, Nigeria. Journal of Agricultural Sciences, 9, 109-117. https://doi.org/10.4038/jas.v9i3.7424

Aigner, D. L. et al. (1977). Formulation and Estimation of Stochastic Frontier Production Function Models. Journal of Economics, 6, 21-37. https://doi.org/10.1016/0304-4076(77)90052-5

Appelbaaum, E., Bailey, T., Berg, P., \& Kalleberg, A. L. (2000). Manufacturing Advantage: Why High-Performance Work Systems Pay Off. Ithaca, NY: Conell University Press.

Batese, G., \& Coelli, T. J. (1995). A Model for Technical Inefficiency Effects in Stochastic Frontier Production Function for Panel Data. Empirical Economic, 20, 325-332. https://doi.org/10.1007/BF01205442

Battese, G. E., \& Coelli, T. (1988). Prediction of Firm Level Technical Efficiencies with a Generalized Frontier Production Function and Panel Data. Journal of Econometrics, 38, 387-339. https://doi.org/10.1016/0304-4076(88)90053-X

Bravo-Ureta, B., \& Pinheiro, A. E. (1993). Efficiency Analysis of Developing Country Agriculture: A Review of the Frontier Function Literature. Agricultural and Resource Economics Review, 22, 88-101. https://doi.org/10.1017/S1068280500000320

Dennis, A., \& Romanus, N. (2018). Adoption of Recommended Plan Oil Palm Processing Technology in Isoko North Local Government Area, Nigeria. Asian Journal of Agricultural Extension, Economics \& Sociology, 24, 1-8.

https://doi.org/10.9734/AJAEES/2018/39987

FAO (2016). Mission FAO/PAM: D'Evaluation des Recoltes et de la Securite Alimentaire en Republique Centrafricaine, Rapport Special.

Forrest, T. (2019). Politics and Economic Development in Nigeria: Updated Edition. Routtede. https://doi.org/10.4324/9780429302367

Fuss, M., McFadden, D., \& Mundlak, Y. (1978). A Survey of Functional Forms in the Economic Analysis of Production. History of Economic Thought Chapters, 1.

Huang, X., \& Liu, J. G. (2020). Regional Economic Efficiency and Its Influencing Factors of Beijing Tianjin HEIBEI Metopolitans in China Bsed on a Heterogeneity Stochastic Frontier Model. Chinese Geographical Science, 30, 30-44. https://doi.org/10.1007/s11769-019-1089-0

Hwu, S. T., Fu, T.-T., \& Tsay, W.-J. (2016). Estimation and Efficiency Evaluation of Stochastic Frontier Models with Interval Dependent Variables.

Kumbhakar, S. C., Ghosh, S., \& McGuckin, J. T. (1991). A Generalized Production Frontier Approach for Estimating Determinants of Inefficiency in US Dairy Farms. Journal of Business \& Economic Statistics, 9, 279-286. https://doi.org/10.1080/07350015.1991.10509853

Lorenz, E., \& Valeyre, A. (2005). Organisational Innovation, Human Resource Management and Labor Market Structure: A Comparison of the EU-15. Journal of Industrial Relations, 47, 424-442. https://doi.org/10.1111/j.1472-9296.2005.00183.x

Ojo, S. O., \& Ajibefun, I. (2000). Effect of Training on Labour Productivity and Efficiency in Oil Palm Production in Ondo State Nigeria. Journal of Sustainable Agriculture and the Environment, 2, 275-279.

Porter, M. E. (1998). The Adam Smith Address: Location, Clusters, and the "New" Microeconomics of Competition. Business Economics, 33, 7-13.

Tafti, S. F., Shahnaz, M. J., \& Emami, A. (2012). Explaining Evolutionary Trend of Strategic Planning from Traditional Economy to Innovation. Procedia-Social and Behavioral Sciences, 58, 56-65. https://doi.org/10.1016/j.sbspro.2012.09.978

Takeshima, H., Nin-Pratt, A., \& Diao, X. S. (2013). Mechanization and Agricultural 
Technology Evolution, Agricultural Intensification in Sub-Saharan Africa Typology of Agricultural Mechanization in Nigeria. Journal of Agriculture Economics, 95, 1230-1236. https://doi.org/10.1093/ajae/aat045

Tey, Y. S., Brindal, M., Darham, S., Sidique, S. F. A., \& Djama, M. (2020). Factors Influencing Sustainability Certification among Plantation Companies in Malaysia: A Panel Approach. Sustainable Production and Consumption, 22, 231-238. https://doi.org/10.1016/j.spc.2020.03.005

UNDP-Madagascar, U. N. D. P. (2003). Antananarivo; 2003. Rapport national sur le développement humain-Madagascar, 274.

Wanke, P., Chen, Z. F., Zheng, X., \& Antunes, J. (2020). Sustainability Efficiency and Carbon Inequality of the Chinese Transportation System. Journal of Environmental Management, 260, Article ID: 110163. https://doi.org/10.1016/j.jenvman.2020.110163

$\mathrm{Wu}$, J. Z. et al. (2020). Impacts of Agricultural Industrial Agglomeration on China's Agricultural Energy Efficiency. Journal of Cleaner Production, 260, Article ID: 121011. https://doi.org/10.1016/j.jclepro.2020.121011 